\title{
Follow-up study of spinal accessory-facial nerve anastomosis with special reference to the electromyographic findings
}

\author{
C-A. Thulin, I. PETERSÉn, AND L. GRANHOLM \\ From the Department of Neurological Surgery and the Laboratory of Clinical Neurophysiology, Sahlgrenska \\ Hospital, University of Gothenburg, Gothenburg, Sweden
}

Since the first suggestions for anastomosis between the spinal accessory and facial nerves (Drobnik, 1879; Fauré, 1898; Ballance, 1919) clinical papers have appeared regularly (e.g., Kennedy, 1901; Ballance, Ballance, and Stewart, 1903; Cushing, 1903; Coleman and Walker, 1950; McKenzie and Alexander, 1950; Love and Cannon, 1951; Svien and Karavitis, 1954; Caldwell, 1958; Bragdon and Gray, 1962; Love, 1962) but such studies lack correlation with electromyographic findings on the facial musculature during its reinnervation. In this paper a long-term follow-up study of 18 patients, treated with spinal accessory-facial anastomosis after an intracranial facial nerve lesion, is reported, with special attention to E.M.G. data and their relationship to the clinical return of function to the facial muscle. Facilitating and inhibiting effects have also been studied.
THE PRESENT SERIES

The material consists of 18 patients with spinal accessory facial nerve crossing, performed two weeks to 12 months $\vec{w}$ after the onset of facial paralysis due to removal of tumours of the pontine angle (Table I). The follow-up period after the anastomosis varies from six months too nine years. The age and sex distributions are indicated in Table $I$.

In 15 patients the anastomotic procedure consisted $\theta$ for partial section of the spinal accessory nerve, using tion sternocleidomastoid branch of the nerve when possibie. In the remaining three cases the whole cross-section of $\mathrm{f}_{\mathrm{x}} \mathrm{e}$ accessory nerve was sutured to the distal portion of the facial nerve.

FOLLOW-UP STUDIES The patients were subjected two or three clinical examinations at different interea is in the post-operative period.

TABLE I

SUMMARY OF E.M.G. DATA AND CLINICAL RECONSTITUTION OF FACIAL MUSCLE FUNCTION IN PRESENT SERIES

$\begin{array}{llll}\text { Case No. } & \begin{array}{l}\text { Sex and Age } \\ \text { at Time of }\end{array} & \begin{array}{l}\text { Total }(T) \text { or Interval between } \\ \text { Partial }(P)\end{array} \\ \text { Nerve } & \begin{array}{l}\text { Suture of Paralysis Nerve } \\ \text { Crossing }\end{array} & \begin{array}{l}\text { Spinal } \\ \text { Accessory } \\ \text { And Nerve Anastomosis and Follow-up }\end{array} \\ & \text { Nerve }\end{array}$

Symmetry
of Facial
Tone at
Rest

\begin{tabular}{|c|c|c|c|c|}
\hline $\begin{array}{l}\text { Orbicularis } \\
\text { Oris Muscl }\end{array}$ & & $\begin{array}{l}\text { Orbicularis } \\
\text { Oculi Musc }\end{array}$ & & $\begin{array}{l}\text { Voluntary } \\
\text { Facial }\end{array}$ \\
\hline $\begin{array}{l}\text { Voluntary } \\
\text { Raising of } \\
\text { Mouth }\end{array}$ & E.M.G. & $\begin{array}{l}\text { Voluntary } \\
\text { Closing of } \\
\text { Eye }\end{array}$ & E.M.G. & $\begin{array}{l}\text { without } \\
\text { Concomitan } \\
\text { Eleventh } \\
\text { Nerve Actio }\end{array}$ \\
\hline
\end{tabular}

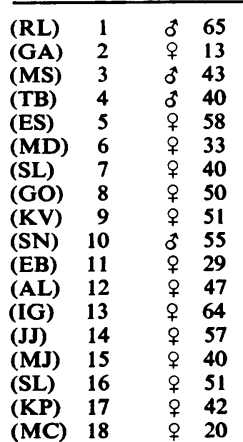

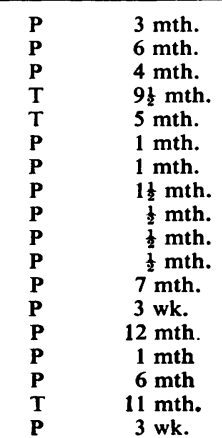

$$
\begin{aligned}
& 9 \text { yr. } 1 \text { mth. } \\
& 8 \text { yr. } 8 \text { mth. } \\
& 6 \text { yr. } 2 \text { mth. } \\
& 5 \text { yr. } 8 \text { mth. } \\
& 5 \text { yr. } 5 \text { mth. } \\
& 5 \text { yr. } 2 \text { mth. } \\
& 4 \text { yr. } 8 \text { mth. } \\
& 4 \text { yr. } 7 \text { mth. } \\
& 4 \text { yr. } 3 \text { mth. } \\
& 4 \text { yr. } \\
& 3 \text { yr. } 7 \text { mth. } \\
& 2 \text { yr. } 4 \text { mth. } \\
& 2 \text { yr. } 2 \text { mth. } \\
& 1 \text { yr. } 7 \text { mth. } \\
& 1 \text { yr. } 10 \text { mth. } \\
& 1 \text { yr. } 7 \text { mth. } \\
& 1 \text { yr. } 1 \text { mth. } \\
& 6 \text { mth. }
\end{aligned}
$$

$\begin{array}{ll}\text { Yes } & \text { Yes } \\ \text { No } & \text { Yes } \\ \text { No } & \text { Yes } \\ \text { No } & \text { Yes } \\ \text { No } & \text { Yes } \\ \text { Yes } & \text { Yes } \\ \text { Yes } & \text { Yes } \\ \text { Yes } & \text { Yes } \\ \text { Yes } & \text { Yes } \\ \text { Yes } & \text { No } \\ \text { Yes } & \text { Yes } \\ \text { Yes } & \text { Yes } \\ \text { Yes } & \text { Yes } \\ \text { Yes } & \text { Yes } \\ \text { Yes } & \text { Yes } \\ \text { Yes } & \text { Yes } \\ \text { No } & \text { Yes } \\ \text { Yes } & \text { Yes }\end{array}$

\begin{tabular}{l} 
IIIb \\
IIIa \\
IIIb \\
IIIa \\
IIIb \\
IIIb \\
- I \\
IIIa \\
IIb \\
\hline IIb \\
\hline IIb \\
$\frac{\text { IIIb }}{\text { IIIb }}$ \\
IIa
\end{tabular}

Yes
Yes
Yes
Yes
Yes
Yes
No
Yes
Yes
No
Yes
Yes
Yes
Yes
No
Yes
Yes
No

\begin{tabular}{c} 
IIb \\
IIa \\
IIIb \\
IIIb \\
IIb \\
IIb \\
\hline I \\
IIb \\
I \\
\hline IIb \\
\hline IIb \\
\hline IIIb \\
IIb \\
I
\end{tabular}


E.M.G. STUDIES With four exceptions, the patients were studied by means of electromyography. The electromyographic recordings with monopolar co-axial needle electrodes were made percutaneously from the muscles of the chin and forehead and from the orbicular muscles of the eye and mouth. For the recording a Disa E.M.G. machine was used. Special attertion was given to records obtained during cooperative movements of oral and spinal accessory muscles on the side of nerve crossing and on the intact side as well.

\section{RESULTS}

CLINICAL EXAMINATION For classification of the results of reinnervation we have paid attention to the following factors: (1) normal or practically normal resting facial tone with symmetrical nasolabial folds and eye fissures; (2) ability to close the eye voluntarily; and (3) ability to raise the corner of the mouth.

Nine of the 18 patients complied with all the criteria given and the operations were thus considered as successful. Of the remaining nine patients, eight agreed with two of the required factors listed. They were able to use the risorius, chin, and lip muscles, but either the contraction of the orbicularis oculi muscle or the resting symmetry of the facial tone was completely or partly insufficient. In the remaining case (no. 10) only one of the criteria was fulfilled, although an adequate follow-up time (four years) had elapsed. None of the patients could thus be considered as a complete failure (Table I). We believe, as do others (Martin, 1955; Kettel, 1959), that of the criteria stated above, presence of muscle tone is the most important of clinical signs of muscle reinnervation. In our series, all but five patients demonstrated normal resting symmetry of the face.

Some degree of synkinesia was noted in all patients on the affected side but by no means 'the entire facial musculature was made a single functional unit' (cf., Coleman, 1940). Such movements are probably caused by nerve fibrils straying when growing downwards into different peripheral branches, and/or there may be a failure of maturation of nerve fibres at the suture line with resulting cross stimulation, $c f$. the 'fibre interaction' of Granit, Leksell, and Skoglund (1944) when impulses pass across an anastomosis. Isolated voluntary movements were possible in some of the patients, e.g., voluntary closure of the eye gave only scarcely perceptible movement of the angle of the mouth and not a single grimace-like movement of the face. However, such functional perfection and finely graded use of selective facial muscle groups was seen only exceptionally. In no case was any emotional control or mimic activity demonstrable.

Overaction and mass movement of the face ac- companying any vigorous shrug of the shoulder or rotation of the head was quite marked in 13 of the 18 patients (Table I). From a cosmetic point of view they considered themselves embarrassed and disabled due to the concomitant grimace-like movements of the face in eating or in public performances. By dint of special effort and with continued practice the five exceptional patients gained some success in eliminating the associated mass movements in such a way that a minimal, hardly visible, innervation of the trapezius or the sternocleidomastoid muscle was sufficient to cause a facial contraction. The accomplishment of dissociated facial movements might be a matter of re-educating a fresh part of the shoulder centre, at the junction of the upper and middle thirds of the ascending frontal gyrus, to do the work of the old facial centre in the lower third of the same gyrus, as discussed by Ballance et al. (1903) and by Pool and Pava (1957). Closer associational correspondence in the cortex and in the bulb of hypoglossal and glossopharyngeal motor centres to the face centre has been the incitement for selecting the peripheral bundles of hypoglossal (Brown, 1926; Trumble, 1948; Coleman, 1940; Pool and Pava, 1957; Kessler, Moldaver, and Pool, 1959) or glossopharyngeal nerves (WatsonWilliams, 1927) for anastomosis with the distal segment of the paralysed facial nerve.

Myoclonic contractions or isolated purposeless movements of the reinnervated muscles accompanying restoration of movement after complete nerve degeneration (Ballance and Duel, 1932; Duel, 1933; Fowler. 1939; Collier, 1941) were seen in two of the patients (cases 11 and 14), particularly in the muscles of the chin. The two patients, although conscious of the twitches, were not disturbed by them.

Poor eyebrow and forehead function was noted in all our patients, and has also been noted by others (Coleman, 1940; Trumble, 1948; Martin, 1955; Kessler et al., 1959), when using a hypoglossal-facial nerve crossing technique.

Moderate atrophy and drop of the shoulder on the affected side was noted in most cases and they also demonstrated slight weakened motor function in the shoulder. This was seen, with two exceptions, in spite of the fact that the sternocleidomastoid branch was selected for anastomosis whenever possible. In a few of the patients, where the trapezius branch was involved in the anastomosis, the innervation of the lower portion of the upper half of the trapezius muscle was intact, the scapula held back and up, and the arm could be elevated in abduction almost normally. This might be explained by the fact that in these cases a significant portion of the upper half of the trapezius was innervated by branches from the third and fourth cervical nerves. None of the patients 
complained, however, of any major disability interfering with their habitual profession.

The time interval for the first functional signs of reinnervation to appear varies considerably in our material, namely, from two-and-a-half months to 14 months, with mean intervals of three to six months. Many observers (Kessler et al., 1959) claim that the nerve crossing operation should be done as promptly as possible after injury to the facial nerve. The time factor up to 12 months does not seem to have any effect on the functional outcome of our patients (see Table I). All were operated within a year following the facial nerve paralysis. This agrees with reports by Martin (1955) on facial transplant surgery, who claims that 'those done within one year had the best outcome'. Yet a successful outcome after a delay of two-and-a-half years is occasionally described in the literature (Brown, 1926; McKenzie and Alexander, 1950).

ELECTROMYOGRAPHIC STUDIES To classify our E.M.G. findings recorded from the reinnervated orbicular muscles of the mouth and eye respectively, we have paid attention to the following requirements (Table I). 1, The presence of fibrillary or other denervation potentials and complete absence of voluntarily elicited large action potentials at each position of the needle electrode, i.e., signs of an advanced denervation of the muscles; 2 , the presence of a few (one to three) voluntarily activated

\section{A. Recording from reinnervated side}

$$
1
$$

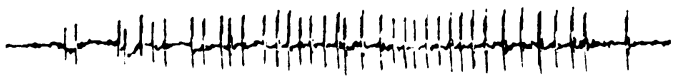

2

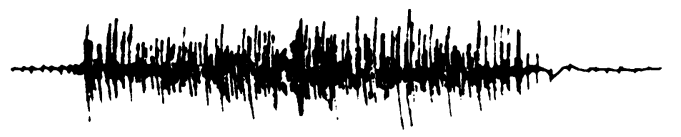

3

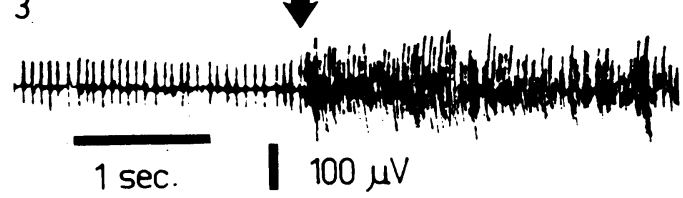

large action potentials at each position of the needle $\frac{\text { o }}{Z}$ electrode, with (group IIa) or without (group IIb) $\mathbb{D}$ denervation potentials; 3 , the presence of voluntary activity consisting of several potentials (more than $\stackrel{\text { ( }}{\complement}$ three), with (group IIIa) or without (group IIIb) denervation potentials.

Considering the reconstituted function of the oral orbicular muscles, nine patients out of 14 studied comply with the third criterion given, thus showing electromyographic evidence of an advanced degree of reinnervation (see Table I). The method, however, does not permit of any quantitative evaluation $-\overrightarrow{0}$ between the patients in this group. Four patients $\frac{C}{\sigma}$ agree with the requirements for group II. In only one $\overline{\bar{c}}$. patient (case 8) is there no electromyographic $\widehat{\Phi}$ evidence of reinnervation obtainable (group I), although this patient clinically has been classified ${ }^{\infty}$ as successful.

Electromyographic evidence of advanced restitu- $\vec{\oplus}$ tion (group III) in the orbicular muscles of the eye is ${ }_{\sigma}^{\omega}$ seen only in three of the 14 patients studied, the majority (eight cases) being referred to group II. In the remaining three patients no electrical signs of ${ }^{\prime}$ reinnervation can be demonstrated (group I).

It might be of interest to look for any possibte relationship between the clinical and electromyō-N graphic examinations. As evident from Table voluntary ability to raise the corner of the mouth seen in all cases except one (case 10). Correlated wi this is the restitution of large action potentials (as

\section{B. Recording from control side}

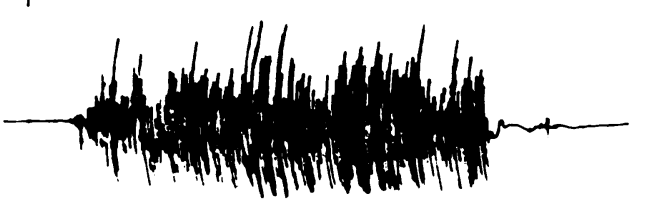

2

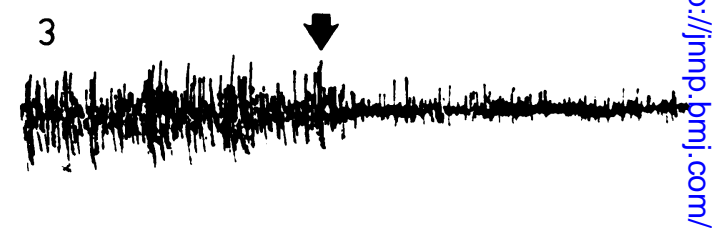

FIG. 1. Case 16, 19 months after anastomosis. Recording from the oral orbicular muscles on reinnervated (Al-A3) and on control $(B I-B 3)$ side. Al and BI: Reconstituted motor unit discharges on voluntary contraction of ora $F_{D}$ muscles. A2-B2: Voluntary elevation of shoulders ipsi-lateral to the recording on each side. The motor dischargeso on reinnervated side indicate the reconstituted spinal accessory-facial pathway. A3-B3: Voluntary contraction of oral orbicular muscles with additional shoulder elevation (at arrows) on the respective side of recording. Theos additional increase in firing of motor units on operated side is opposed to inhibition on control side. 
required for groups II and III) in all but one (case 8) of the 14 cases tested. Such a positive correlation is also found between signs of clinical and electrical reconstitution in the orbicular muscles of the eye, i.e., in 13 out of 14 patients studied. The exceptional patient is case 8 , just mentioned above, As this case has been listed as successful clinically, the electrical signs of advanced denervation obtained in this case seem somewhat puzzling.

Electromyographic illustrations of function following the nerve crossing procedure in two successful cases are seen in Figure 1. Large action potentials are recorded from the upper lip on the reinnervated side with voluntary compressing of the lips (record A1). This also occurs with isolated voluntary contraction of the trapezius muscle by means of ipsilateral shoulder lifting (record A2), indicating a

\section{A. Recording from reinnervated side}
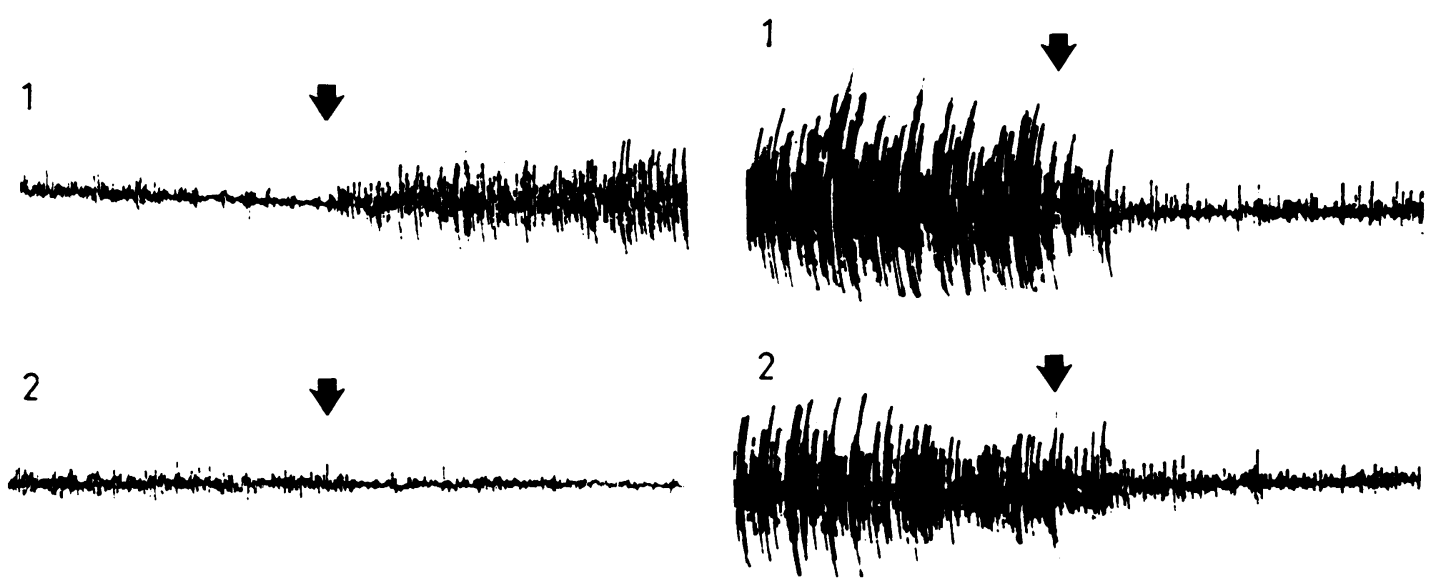

3
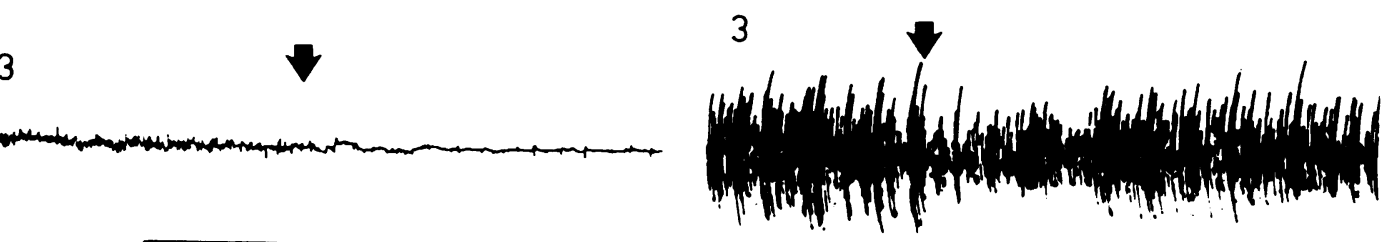

reconstituted spinal accessory-facial pathway. A combination of the two voluntary actions on the operated side is seen in records A3 from case 16 (also in record A1, Fig. 2, from case 5). The effect is characterized, as to be expected, by a marked increase in the large potential activity, as the trapezius action is added to lip movements (see arrows). This increase of activity cannot, of course, be demonstrated on the treated side when moving the contralateral (healthy) shoulder. This instead will elicit a clear and pronounced inhibition of the voluntary activity of the reinnervated oral musculature (record A2 of Fig. 2). Such an inhibition of a test response from the facial muscles of both affected and healthy sides to conditioning voluntary movements of other groups of muscles, with the single exception of the operated spinal accessory men-

\section{B. Recording from control side}

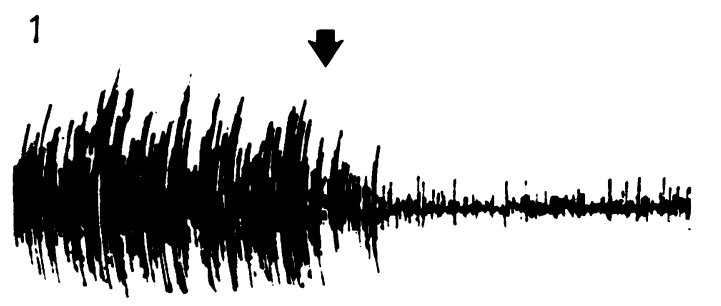

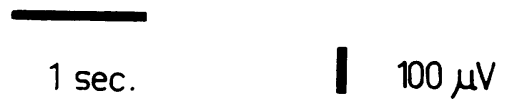

FIG. 2. Case 5, five-and-a-half years after anastomosis. Recording from the oral orbicular muscles on reinnervated (A1-A3) and on control $(B 1-B 3)$ side. AI-B1: Voluntary contraction of oral muscles with additional shoulder elevation (at arrow's) on the reinnervated side in both records. The additional increase in motor unit discharges on operated side is opposed to inhibition on control side. A2: Voluntary contraction of reinnervated oral muscles with additional elevation of shoulder (at arrow) on contralateral (control) side. The motor unit discharges are inhibited. A3-B2: Voluntary contraction of oral orbicular muscles with additional elevation of the leg (at arrows) on the reinnervated side in both records. The motor unit discharges recorded on both reinnervated and control sides are inhibited. B3: Voluntary contraction of the oral orbicular muscles on control side. Note inhibition of the test response during an auditory stimulus (at arrow). 
tioned, is normal, e.g., records $\mathrm{B} 3$ in Fig. 1 and A3, B1, and B2 in Fig. 2, or to other types of conditioning stimuli, e.g., noise (record B3, Fig. 2). This might be due to central (cortical) mechanisms of general inhibition involved in the patient's act of heeding commands given under study; mechanisms which are put out of function due to the nerve-crossing procedure. In the different tests, visual, auditory, and sensory stimuli have been used without any difference in the inhibitory effects recorded.

The facilitatory effect (in records A1, Fig. 2) obtained in case 5 from the oral muscles on the operated side when ipsilateral shoulder shrug is added to their voluntary action is sometimes preceded by a short initial period of electrical depression of some 0.5 to 1 second. This is probably due to the same central action of inhibition involved in attentional mechanisms.

The results described were consistent in all seven patients analysed.

\section{SUMMARY AND CONCLUSIONS}

A long-term follow-up of 18 patients, treated by a spinal accessory-facial nerve anastomosis after intracranial facial nerve lesions, is reported. Special attention is given to electromyographic data and their relationship to the clinical return of facial muscle function.

In nine out of the 18 patients the operations are considered as successful in terms of restored facial tone at rest combined with ability to raise the corner of the mouth and to close the eye voluntarily. None can be considered a complete failure. Such side-effects as synkinesia or mass movement of the face on the reinnervated side accompanying movements in muscles served by the eleventh nerve, as well as moderate atrophy and drop of the shoulder, are seen in most patients and have been discussed.

A close positive correlation is noted between the clinical and electromyographic signs of reinnervation in the orbicular muscles of the mouth and the eye. Inhibition of a test response from the facial muscles of the affected and healthy sides to conditioning voluntary movements of other groups of muscles is regularly met, with the exception of the muscles served bv the operated spinal accessory nerve.

\section{REFERENCES}

Ballance. C. (1919). Essays on the Surgery of the Temporal Bon vol. 2, p. 578. Macmillan, London. Cited from Ballance and Duel (1932).

Ballance, C. A., Ballance, H. A., and Stewart, P. (1903). Operati疋 treatment of chronic facial palsy of peripheral origin. Brit:
med.J., 1, 1009-1013.

Ballance, C., and Duel, A. B. (1932). The operative treatment of facto palsy. Arch. Otolaryng., 15, 1-70.

Bragdon, F. H., and Gray, G. H. Jr. (1962). Differential spin accessory-facial anastomosis with preservation of function trapezius. J. Neurosurg., 19, 981-985.

Brown, A. (1926). Results of hypoglossofacial anastomosis for faciah paralysis in two cases. Surg. Gynec. Obstet., 42, 608.

Caldwell, E. H. (1958). Anastomosis of the branches of the facial and spinal accessory nerves for facial paralysis. Surgery, 4. 978-983.

Coleman, C. C. (1940). Results of facio-hypoglossal anastomosis the treatment of facial paralysis. Ann. Surg., 111, 958-970. and Walker, J. C. (1950). Technic of anastomosis of tis branches of the facial nerve with the spinal accessory for facial
paralysis. Ibid., 131, 960-968.

Collier, D. J. (1941). Discussion on the limitations of operative treatment in traumatic facial paralysis. Proc. roy. Soc. Med., $3 \Phi$ 575-580.

Cushing, H. (1903). The surgical treatment of facial paralysis by ner anastomosis. Ann. Surg., 37, 641-659.

Drobnik (1879). Cited from Ballance and Duel (1932).

Duel, A. B. (1933). History and development of the surgical treatme of facial palsy. Surg. Gynec. Obstet., 56, 382-390.

Fauré, J. L. (1898). Traitemant chirurgical de la paralysie faciale pió anastomose spino-faciale. Congrès de Chirurgie (Paris). Procès-verbeaux, 12, 190.

Fowler, E. P. (1939). Abnormal movements following injury toukg facial nerve. J. Amer. med. Ass., 113, 1003-1008.

Granit, R. Leksell, L., and Skoglund, C. R (1944). Fibre interaef in injured or compressed region of nerve. Brain, 67, 125 49

Kennedy, R. (1901). On the restoration of co-ordinated movertents after nerve-crossing, with interchange of function of the cererat cortical centres. Phil. Trans. B., 194, 127-162.

Kessler, L. A., Moldaver, J., and Pool, J. L. (1959). Hypoglosså facial anastomosis for treatment of facial paralysis. Neur@og (Minneap.), 9, 118-125.

Kettel, K. (1959). Peripheral Facial Palsy. Pathology and Sur Munksgaard, Copenhagen.

Love, J. G. (1962). Surgical treatment of facial paralysis: A modifica tion of spinofacial anastomosis. Proc. Mayo Clin., 37, 404-400

__, and Cannon, B. W. (1951). Nerve anastomosis in the treatment of facial paralysis. Special consideration of the etiologic rote of total removal of tumours of the acoustic nerve. Arch. Surgo 62, 379-390.

Martin, R. C. (1955). Late results of facial nerve repair. Ann. Ot $\frac{\not 1}{\partial}$ (St. Louis), 64, 859-869.

McKenzie, K. G., and Alexander, E., Jr. (1950). Restoration of facâ function by nerve anastomosis. Ann. Surg., 132 411-415. (D)

Pool, J. L., and Pava, A. A. (1957). The Early Diagnosis and Tredment of Acoustic Nerve Tumours. Thomas, Springfield, Illino

Svien, H. J., and Karavitis, A. L. (1954). A technic for anastomosis of the facial nerve and spinal accessory nerve. J. Neurosurg. $11,509-510$.

Trumble, H. C. (1948). Nerve anastomosis in the treatment of facte paralysis. Aust. N.Z. J. Surg., 17, 297-299.

Watson-Williams, E. (1927). Glosso-pharyngeal facial nerse anastomosis. Proc. roy. Soc. Med., 20, 1439-1443. 